Dhaka Univ. J. Biol. Sci. 26(1): 13-27, 2017 (January)

\title{
GROWTH PERFORMANCE AND FATTY ACID PROFILE OF NILE TILAPIA OREOCHROMIS NILOTICUS (LINNAEUS, 1758) FED WITH DIFFERENT PHYTOPLANKTON
}

\author{
Md Babul Hossain, Nahid Sultana ${ }^{1}$, Parvin Noor ${ }^{1}$, Selina Khan ${ }^{2}$, Sharmin \\ Akter Lisa ${ }^{2}$, Mahmuda Begum ${ }^{1}$, Nusrat Jahan Punom, Mst Khadiza Begum, \\ Md Rakibul Hasan ${ }^{1}$ and Mohammad SHamsur RahmaN* \\ Department of Fisheries, Faculty of Biological Sciences, University of Dhaka, \\ Dhaka-1000, Bangladesh
}

Key words: Nile tilapia (Oreochromis niloticus), Phytoplankton, Live feed, Growth performance, Fatty acid composition

\begin{abstract}
The effect of different phytoplankton species on growth, survival and fatty acids composition of Nile tilapia (Oreochromis niloticus) was evaluated for 24 weeks. Treatment-1 was fed with commercial feed as Control, treatment-2 was fed with Spirulina platensis, treatment-3 was fed with Chlorella vulgaris and treatment-4 was fed with mixed phytoplankton (Chlorella vulgaris, Spirulina platensis, Azolla pinnata and Pistia stratiotes). The condition factor of fish found in treatment-3 with Chlorella vulgaris $(1.73 \pm 0.02)$ was significantly higher than that of treatment- 1 as control $(1.56 \pm 0.02)$ at 24 weeks culture period. The specific growth rate of treatment- 4 with mixed phytoplankton diet $(2.00 \pm 0.10)$ was significantly higher than treatment-3 with Chlorella vulgaris $(1.13 \pm 0.05)$ after 24 weeks of rearing. There was no significant difference among the four treatments in case of average daily gain, feed conversion ration and survival rate. The use of different phytoplankton such as Spirulina platensis, Chlorella vulgaris and Azolla pinnata influence the fatty acid profiles of Nile tilapia. Findings also showed that the amount of eicosapentaenoic acid (EPA) in treatment-3 fed with Chlorella vulgaris $(1.83 \pm 0.22)$ was highly significant than the other treatments. The highest amount of docosahexaenoic acid (DHA) was found in treatment-1 fed with commercial feed $(2.70 \pm 0.53 \%)$ and lowest in treatment- 2 with Spirulina platensis $(0.06 \pm 0.02 \%)$. Among 19 unsaturated fatty acid, the highest concentration of PUFAs were recorded in treatment-3 $(42.55 \pm 3.46 \%)$ fed with Chlorella vulgaris. The findings of this study suggest that raising Nile tilapia with Chlorella vulgaris and Spirulina platensis in ponds may improve the growth and fatty acid profile of the fish.
\end{abstract}

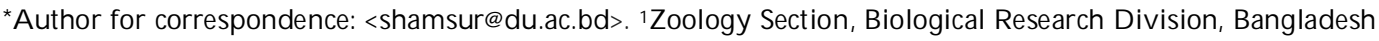
Council for Scientific and Industrial Research (BCSIR), Dhaka 1000, Bangladesh. ${ }^{2}$ Institute of Food Science and Technology (IFST), Bangladesh Council for Scientific and Industrial Research (BCSIR), Dhaka-1000, Bangladesh.
} 


\section{Introduction}

More than $50 \%$ of the world population rely on fish as a principal source of animal protein $^{(1)}$. Nile tilapia is a widely distributed freshwater fish and the most important commercially cultured fish species. FAO reported that world's total tilapia production in 2012 was 9.45 million tons. At present, tilapia is cultured commercially in almost 100 countries worldwide, with over 98 per cent of the production occurring outside their original habitats( ${ }^{(2)}$. Nile tilapia (Oreochromis niloticus) was introduced in Bangladesh in 1974 (http://en.banglapedia.org/Index.php?title=Exotic_Fish). In July 1994 another promising strain, Genetically Improved Farmed Tilapia (GIFT), a synthetic strain of $O$. niloticus, was introduced from Philippines under a project of World Fish named 'Dissemination and Evaluation of Genetically Improved Tilapia in Asia'. To increase growth and production of reared fish, feed is a principal factor ${ }^{(3)}$. Different sources of conventional plant oilseed meals like as cottonseed, rapeseed meal ${ }^{(4)}$ and green algae ulva meal (5) are used to minimise high cost, fluctuating quality and uncertain availability of fish meal in tilapia diets. Recently, interests are growing on the fatty acid composition of fish, especially when evaluating the suitability of plant sources to replace fish meal in fish feed.

For achieving maximum growth and survival of the young finfish and shellfish, live food organisms are used nowadays. They contain all the nutrients such as essential proteins, lipids, carbohydrates, vitamins, minerals, amino acids and fatty acids and hence are commonly known as "living capsules of nutrition"(6). Live food contains a high quantity of polyunsaturated fatty acids (PUFA) which revert the level of triglycerides, a major source of metabolizable energy that are directly correlated to the growth of $\operatorname{organism}^{(7)}$.

Spirulina is a cyanobacteria, which is consumed by humans and other animals. About $60 \%(51-71 \%)$ protein contained by dried Spirulina (https://en.wikipedia.org/wiki/ Spirulina (dietary_supplement)). Single cell green algae, Chlorella is a significant source of protein, other essential nutrients; $45 \%$ protein, $20 \%$ fat, $20 \%$ carbohydrate, $5 \%$ fibre, and $10 \%$ minerals and vitamins were found when dried (https:/en.wikipedia.org/wiki/ Chlorella). Aquatic fern Azolla also known as mosquito fern or duckweed fern, is rich in proteins, essential amino acids, vitamins and minerals (https:/en.wikipedia.org/wiki/ Azolla).

The predominant polyunsaturated fatty acids in fish oil are the omega-3 fatty acids having either five or six double bonds. Fish oils are protective against heart disease, stroke and possibly diabetes and other diseases as well( ${ }^{(8)}$. Eicosapentaenoic acid (EPA) and docosahexaenoic acid (DHA) are more important polyunsaturated fatty acids. There are about seven omega-3 fatty acids in fish derived from the microalgae and plankton in the food chain that fish consume( ${ }^{(9)}$. 
The objective of the present study was to estimate the growth performance, survival rate, fecundity and fatty acid profile of Nile tilapia fed with different phytoplankton.

\section{Materials and Methods}

Experimental Set-up: The investigation was conducted in the wet laboratory at Zoology Section, Biological Research Division, Bangladesh Council of Scientific and Industrial Research (BCSIR) in 2015. The experiment was designed as four treatments where treatment-1 (T1) was fed with commercial feed of Saudi Bangla Fish Feed Ltd. (SBF) as control, treatment-2 (T2) was fed with Spirulina platensis, treatment-3 (T3) was fed with Chlorella vulgaris and treatment-4 (T4) was fed with mixed feed (Azolla pinnata, Chlorella vulgaris, Spirulina platensis and Pisita stratiotes). Four small concrete ponds (each with $10 \times 6 \times 2.25 \mathrm{feet}^{3}$ ) were used for the experiment. All small ponds were washed by water, sun dried for 2 days, filled up with tap water and labelled according to experimental design.

Fry of tilapia (O. niloticus) $(1.57 \pm 0.01 \mathrm{~cm}$ and $0.043 \pm 0.002 \mathrm{~g})$ were collected from Jahane Nijam Bohumukhi Matshya Hatchery, Manikgonj, Bangladesh and carried in oxygenated bags with water in the laboratory. Before stocking, tilapia fries were acclimatized in laboratory conditions with a temperature of $25 \pm 2^{\circ} \mathrm{C}$ adjusted by using thermostatically controlled heaters, $\mathrm{pH} 7 \pm 1$, dissolved oxygen level 3 - $6 \mathrm{mg} \Lambda$ with continuous aeration and at that time no feed was served. The culture units were stocked with a total of 1000 fry of tilapia coming from the same cohort where each pond contained 250 fry. From second day of stocking, feed was given at a rate of $10 \%$ of fish body weight with $15 \%$ supplementary feed (wheat bran and Moringa oliefera leaf). Feed quantity increment in every subsequent six weeks was done by percentages of 7, 5 and 4 of body weight, respectively. Each ration was divided into two equal parts, one portion was offered at 10.00 a.m. while the other at 5.00 p.m. Fishes were reared for 24 weeks from May, 2015 to October, 2015.

Water quality: Physico-chemical parameters of water such as water temperature, dissolve oxygen, light intensity, $\mathrm{pH}$, conductivity, total dissolved substance, Nitrite content and ammonia were recorded three times in a week using mercury thermometer, DO meter (HANNA, HI-9146, USA), Digital lux meter (MEXTECH, LX-1010B, India), pH meter (HANNA, HI-8424, USA), Conductivity/TDS meter (Jenway, Model 4510, UK), respectively.

Estimation of Growth performance: Growth parameters (lengths and weights) of the fingerlings were monitored consequently one time at the interval of 6 weeks where 10 samples were measured randomly at a time. The fish were individually weighed by using a sensitive weighing balance. Body length was measured on board and immediately returned to the water of the same fish pond. The data were used to calculate 
growth, condition factor, feed conversion ratio and survival rate using the following formulae:

1. Condition factor were calculated by the following formula as suggested by Hile (10). Condition factor $=$ Body weights in gm $/(\text { Body length in } \mathrm{cm})^{3} \times 100$

2. Average daily gain was calculated by the following formula as suggested by Hawkins et al. (11).

$\mathrm{ADG}=\frac{\text { Mean final fish weight }- \text { Mean initial fish weight) }}{\text { Time (Final time }- \text { Initial time) }}$

3. Specific growth rate was calculated by the following formula as suggested by Hewett et al (12)

$\operatorname{SGR}(\%)=\frac{(\text { In Wt }- \text { In W1) }}{\text { (Final time }- \text { Initial time })} \times 100$

where, In $\mathrm{Wt}=$ Natural $\log$ of weight at time $\mathrm{T}$ and In $\mathrm{W}_{1}=$ Natural $\log$ of initial weight

4. Feed conversion ratio (FCR) was determined by Hewett and Johnson (13).

$\mathrm{FCR}=\frac{\text { Feed }(\mathrm{g}) \text { consumed by the fish }}{\text { Weight }(\mathrm{g}) \text { grain of the fish (Final weight }- \text { Initial weight) }}$

5. Survival rate was determined by Cheikyula and Ofojekwu (14)

Survival rate $(\%)=\frac{\text { No. of actual fish survived }}{\text { No. of actual fish stocked }} \times 100$

Fecundity determination: Matured Nile tilapia was collected from four experimental ponds. Gravimetric methods were followed to determine the fecundity of fish ${ }^{(15)}$. The external connective tissues were removed from the surface of the ovaries. Moisture of the ovaries was removed with the help of blotting paper. An amount of $0.01 \mathrm{~g}$ of each ovary was taken separately from anterior, middle and posterior regions of each lobe. The number of matured and immature eggs for each portion were sorted out and counted with the help of a needle and magnifying glass. The mean number of eggs in $0.01 \mathrm{~g}$ was determined and then multiplied by the total weight of the ovary, which gave the total number of eggs.

Fatty acids estimation: Fat and fatty acids were extracted from fish by hydroelectric method. Fat were hydrolysed into ether and then methylated to fatty acids methyl esters (FAMEs). FAMEs were separated by gas chromatography (GC). The profiling of fatty acids was done by following chromatographic method described by Nichols et al. (16).

Statistical analysis: Variations in growth and fatty acid composition of fish were analysed using one-way ANOVA followed by Tukey's HSD post hoc for multiple comparisons. Data were presented as mean \pm SEM and evaluated by using the statistical 
package of SPSS for Windows version 20.0 (SPSS, Inc) with the level of significance at $\mathrm{p}<0.05$.

\section{Results and Discussion}

Water quality: Water quality parameters like - temperature, $\mathrm{pH}$, dissolved oxygen, conductivity, light intensity and TDS were found to be almost statistically similar in each treatment (Table 1).

Table 1. Water quality parameters in Nile tilapia, Oreochromis niloticus ponds under different treatments during the study period.

\begin{tabular}{lllll}
\hline Parameters & \multicolumn{3}{c}{ Diet type (treatment ponds) } \\
\cline { 2 - 5 } & Commercial feed & Spirulina & Chlorella & Mixed feed \\
\hline Temperature $\left({ }^{\circ} \mathrm{C}\right)$ & $28.50 \pm 1.11$ & $28.40 \pm 0.94$ & $28.32 \pm 1.15$ & $28.50 \pm 1.14$ \\
$\mathrm{pH}$ & $8.05 \pm 0.46$ & $7.51 \pm 0.02$ & $7.97 \pm 0.46$ & $7.87 \pm 0.37$ \\
Dissolved oxygen $(\mathrm{mg} /)$ & $6.01 \pm 0.98$ & $4.98 \pm 0.30$ & $5.55 \pm 0.74$ & $5.49 \pm 0.28$ \\
Conductivity $(\mu \mathrm{s} / \mathrm{cm})$ & $453.40 \pm 18.01$ & $438.20 \pm 11.16$ & $429.40 \pm 8.20$ & $445.20 \pm 15.74$ \\
Light intensity & $37.60 \pm 13.28$ & $45.30 \pm 13.99$ & $39.60 \pm 11.48$ & $39.99 \pm 09.91$ \\
TDS $(\mathrm{mg} /$ ) & $242.20 \pm 16.98$ & $243.50 \pm 22.89$ & $238.00 \pm 26.01$ & $233.20 \pm 16.70$ \\
\hline
\end{tabular}

Hussain ${ }^{(17)}$ reported that water quality parameters for optimal survival and growth of O. niloticus were temperature ranging from 25.0 to $30.0^{\circ} \mathrm{C}$, dissolved oxygen $4.0-8.0 \mathrm{mg} /$ and $\mathrm{pH} 6.5$ - 9.0 that are in conformity with our records. Dagne et al. reported that water quality parameters such as dissolved oxygen, water temperature and $\mathrm{pH}$ regulate growth of $O$. niloticus because their presence was important for optimum feeding, growth and excretion of wastes in water(18).

\section{Growth performance of Nile tilapia}

Condition factor: After 24 weeks of culture, the highest value of condition factor (K) was observed in tilapia of treatment-3 $(1.73 \pm 0.02)$ fed with Chlorella vulgaris and the lowest value was found in treatment- $1(1.56 \pm 0.02)$ fed with commercial feed (control) (Fig. 1).

Charo-Karisa et al. observed K value for O. niloticus in pelleted feed $(3.86 \pm 0.40)$ and in natural feed $(3.71 \pm 0.37)$ at low temperature ${ }^{(19)}$. According to Khallaf et al. the condition factor of fish depends on a number of factors such as stress, sex, season, availability of feeds and other water quality parameters ${ }^{(20)}$. In this study, condition factor of fish samples in treatment-3 ( $\mathrm{K}=1.73)$ was high. As condition factor indicates the relationship between length and weight, so it may be due to feeding habits as well as good water quality parameters. 
Average daily gain: At the end of 24 weeks of rearing, the average daily gain was observed to be the highest in treatment-2 $(0.45 \pm 0.09)$ fed with Spirulina platensis and the lowest was observed in control $(0.31 \pm 0.03)$. There was no significant difference among the treatments at $5 \%$ level of significance (Fig. 2).

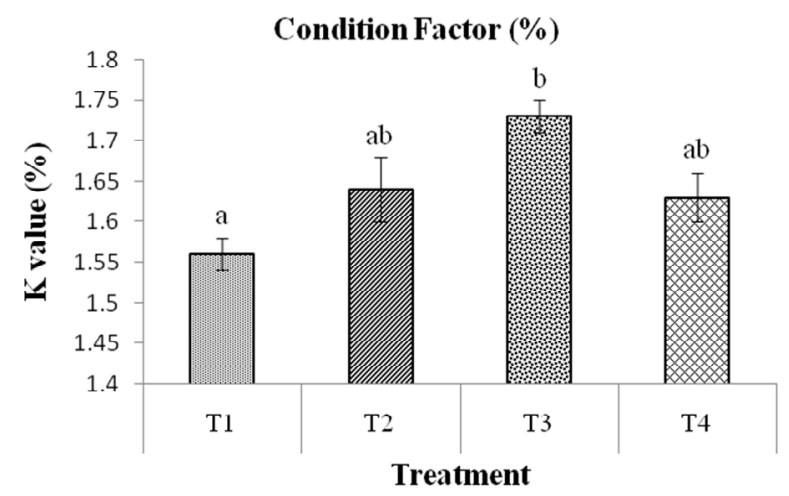

Fig. 1. Condition factor, $\mathrm{K}(\%)$, (mean $\pm \mathrm{SEM})$ of tilapia fish cultured in four different treatments. Bars (Mean \pm SEM) with different superscripts represented significantly different (ANOVA, HSD; $\mathrm{p}<0.05$ ).

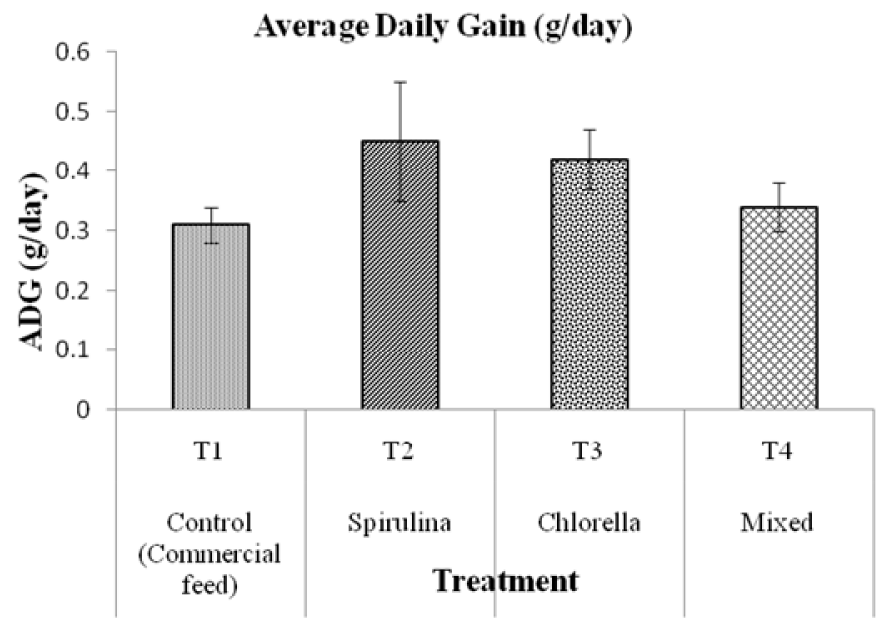

Fig. 2. Average daily gain, ADG (g/day), (mean \pm SEM) of tilapia fish cultured in four different treatments. Bars (mean \pm SEM) with no superscripts represented statistically insignificant (ANOVA, HSD; $\mathrm{p}<0.05$ ).

Commercial feed gave the highest ADG in one study by Chakraborty and Mirza (21) but in our study we found higher ADG using Spirulina platensis and Chlorella vulgaris rather commercial feed though the difference is insignificant. 
Specific growth rate: The highest specific growth rate $(2.00 \pm 0.10)$ was achieved by treatment-4 fed with mixed phytoplankton and the lowest value $(1.13 \pm 0.05)$ in treatment-3 fed with Chlorella vulgaris. Fig. 3 shows specific growth rate (SGR) of treatment- 4 was significantly different from treatment- 2 and treatment- 3 at 24 weeks of rearing. Olvera-Novoa et al. (22) reported that specific growth rate of Nile tilapia was significantly improved when fed on diets containing Azolla pinnata, Medicago sativa, Penniseetum purpureum.

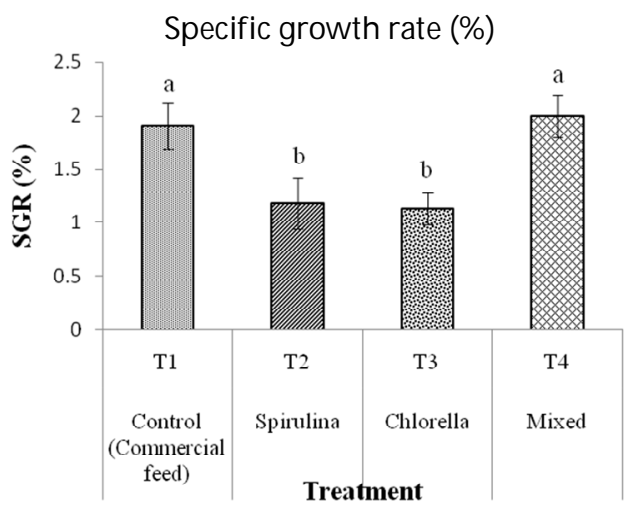

Fig. 3. Specific growth rate, SGR (\%), (mean \pm SEM) of tilapia fish cultured in four different treatments. Bars (mean \pm SEM) with different superscripts represented significantly different (ANOVA, HSD; $\mathrm{p}<0.05$ ).

Feed conversion ratio: The highest feed conversion ratio was found $(3.38 \pm 0.60)$ in treatment-3 fed with Chlorella vulgaris and lowest feed conversion ratio $(1.32 \pm 0.09)$ in treatment- 4 fed with mixed phytoplankton. There was no significant difference found among all treatments at 24 weeks of culture period (Fig. 4).

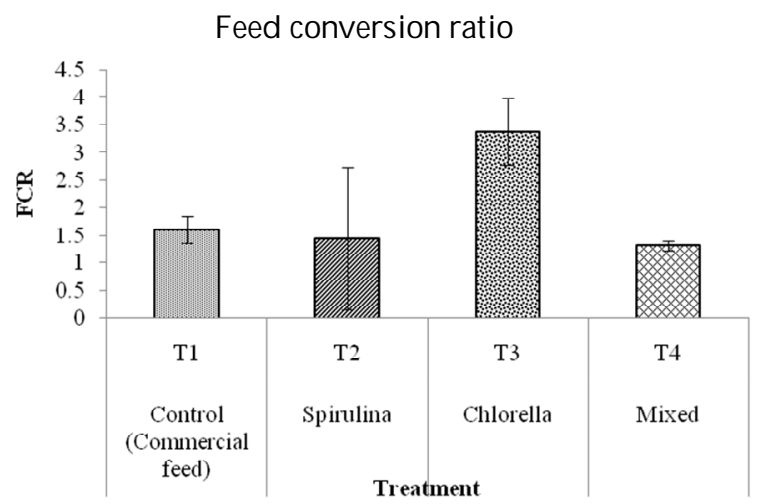

Fig. 4. Feed conversion ratio, FCR, (mean \pm SEM) of tilapia fish cultured in four different treatments. Bars (mean \pm SEM) with no superscripts represented no significant difference (ANOVA, HSD; $\mathrm{p}<0.05$ ). 
Doolgindachabaporn(23) found that the FCR value of Anabas testudineus ranges from 1.8 to 3.0 and Akand et al.(24) found FCR value 2.0 to 2.7 in case of Heteropneustes fossilis. Ogunji and Wirth ${ }^{25)}$ claimed that FCR was 1.19 when they used fish meal diets and that indicated the most efficient utilization of feed by O. niloticus fingerlings. However, in our study FCR value of tilapia in treatment- 4 fed with mixed phytoplankton indicates better feed conversion than other treatments. Therefore, better value of FCR attained by feeding mixed phytoplankton may improve the growth of cultured fish.

Survival rate: The highest survival rate was recorded in treatment-4 $(92.8 \%)$ fed with mixed diet and the lowest was observed in treatment-3 (88.4\%) fed with Chlorella vulgaris after 24 weeks of culture (Fig. 5). High survival rate (90\%) was observed with rapid changes in temperature used for Egyptian (Lake Manzala) strain of blue tilapia reported by Patricio(26). These results are in agreement with Dan and Little ${ }^{(27)}$ who explained that tilapia exhibited similarly high survival rates in deep and shallow ponds (97 - 100\%).

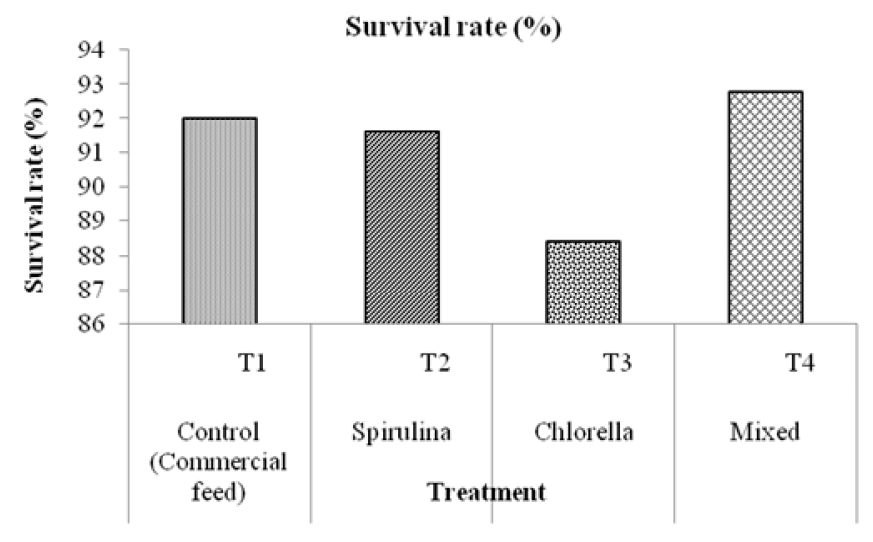

Fig. 5. Survival rate (\%) of tilapia fish cultured in four different treatments.

Fecundity analysis: The highest fecundity was found in treatment-3 (2212 \pm 14$)$ fed with Chlorella vulgaris and the lowest fecundity was found in treatment-4 $(968 \pm 176)$ fed with mixed phytoplankton. There were significant differences among all treatments (Fig. 6).

Duponchelle et al. (28) observed fecundity of O. niloticus ranged from 149 to 2797, for fish weighing between 36 and $975 \mathrm{~g}$ in 1995; and from 178 to 1898, for fish weighing between 78 and $501 \mathrm{~g}$ in 1996. These findings confirm that fecundity in O. niloticus is variable.

Fatty acid profiling: The fatty acid content of fish indicates that fish are superior in terms of the nutritional value. The saturated fatty acid (SFA) composition of Nile tilapia (O. niloticus) is presented in Table 2. Data referring to the fatty acid composition of the different diets showed the proportion of total saturated fatty acids (SFA) was higher in 
treatment-3 fed with Chlorella vulgaris, as compared to the other three treatments. Most abundant concentration of saturated fatty acids such as palmitic, myristic, arachidic and stearic acids were found in Nile tilapia fed with Chlorella vulgaris. Also the highest amount of individual saturated fatty acid (SFA) proportion was observed in treatment-3 fed with Chlorella vulgaris.

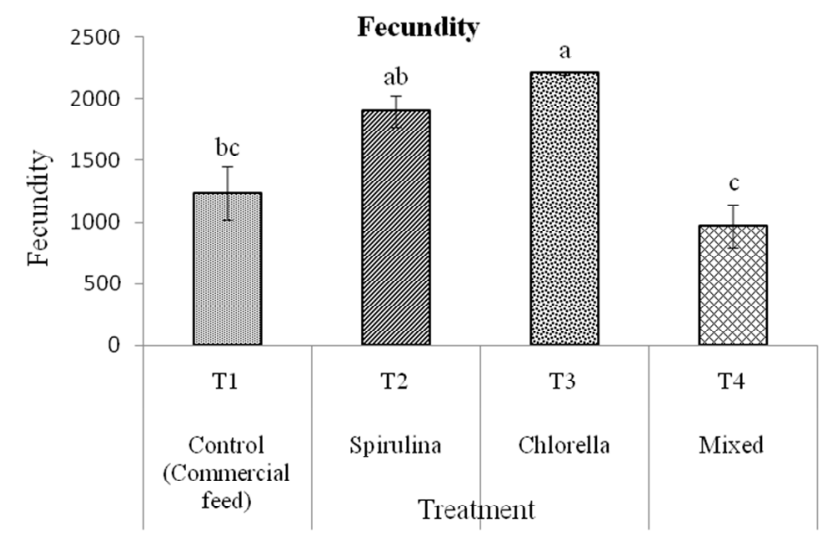

Fig. 6. Fecundity variations of Nile tilapia with four different treatments after 24 weeks of rearing. Bars (mean $\pm \mathrm{SEM}$ ) with different superscripts represented significantly different (ANOVA, HSD; $\mathrm{p}<0.05$ ).

Table 2. Saturated fatty acids (SFA) profile of Nile tilapia (O. niloticus) in four different treatments. All data expressed as mean \pm SEM and percentages. (- indicates not detected).

\begin{tabular}{lcccc}
\hline Fatty acids (C:D) & \multicolumn{4}{c}{ Treatments } \\
\cline { 2 - 5 } & $\mathrm{T} 1$ & $\mathrm{~T} 2$ & $\mathrm{~T} 3$ & $\mathrm{~T} 4$ \\
\hline Myristic acid $(14: 0)$ & $1.19 \pm 0.55$ & $1.52 \pm 0.32$ & $1.30 \pm 0.04$ & $1.35 \pm 0.10$ \\
Pentadecylic acid $(15: 0)$ & $0.36 \pm 0.04$ & $0.70 \pm 0.13$ & $0.79 \pm 0.01$ & $0.67 \pm 0.08$ \\
Palmitic acid $(16: 0)$ & $20.63 \pm 0.43$ & $23.27 \pm 1.21$ & $22.13 \pm 0.37$ & $24.17 \pm 0.32$ \\
Margaric acid $(17: 0)$ & $0.19 \pm 0.10$ & $0.22 \pm 0.03$ & $0.22 \pm 0.00$ & $0.21 \pm 0.02$ \\
Stearic acid $(18: 0)$ & $8.56 \pm 0.08$ & $7.64 \pm 0.63$ & $9.10 \pm 1.50$ & $6.87 \pm 1.02$ \\
Arachidic acid $(20: 0)$ & $1.16 \pm 1.11$ & $1.09 \pm 0.25$ & $2.33 \pm 0.53$ & $0.36 \pm 0.12$ \\
Behenic acid (22:0) & - & - & - & $0.31 \pm 0.15$ \\
\hline Total SFA & $32.09 \pm 2.31$ & $34.44 \pm 2.57$ & $35.87 \pm 2.45$ & $33.94 \pm 1.81$ \\
\hline
\end{tabular}

In this study, the highest amount of myristic acid was found in treatment-2 with Spirulina platensis $(1.52 \pm 0.32 \%)$ and the lowest in treatment-1 in control $(1.19 \pm 0.55 \%)$. The highest amount of stearic acid was found in treatment-3 $(9.10 \pm 1.50 \%)$ with Chlorella vulgaris and the lowest in treatment- $4(6.87 \pm 1.02 \%)$ with Spirulina platensis. The highest proportion of stearic acid $(5-8 \%)$ was found from three tilapia species (O. macrochir, Tilapia rendalli and O. niloticus) in Madagascar ${ }^{(29)}$. 
In this investigation, the highest amount of palmitic acid was found in treatment- 4 $(24.17 \pm 0.32 \%)$ fed with mixed phytoplankton and the lowest in treatment-1 $(20.63 \pm$ $0.043 \%$ ). There was no significant difference among all the treatments at 0.05 levels. Rasoarahona et al.(29) reported that 15 - 21\% of palmitic acid was found from three tilapia species (O. macrochir, T. rendalli and O. niloticus) in Madagascar during three seasons.

Table 3 gives the mean weight percentage of 19 unsaturated fatty acids (both MUFA and PUFA) of Nile tilapia (O. niloticus). Among them, high level of oleic, vaccenic acid, palmitoleic and arachidonic acids observed as a characteristics property of Nile tilapia ${ }^{(30)}$.

Table 3. Mono unsaturated fatty acids (MUFA) and poly unsaturated fatty acids (PUFA) profile of Nile tilapia (O. niloticus) in four different treatments. All data expressed as mean $\pm \mathrm{SEM}$ and percentages. (- indicates not detected).

\begin{tabular}{|c|c|c|c|c|}
\hline \multirow{2}{*}{$\begin{array}{l}\text { Fatty acids }(C: D) \\
\text { Monounsaturated fatty acids }\end{array}$} & \multicolumn{4}{|c|}{ Treatment } \\
\hline & $\mathrm{T} 1$ & $\mathrm{~T} 2$ & T3 & $\mathrm{T} 4$ \\
\hline Palmitoleic acid (16:1) & $0.86 \pm 0.43$ & $3.07 \pm 1.07$ & $3.07 \pm 0.25$ & $2.13 \pm 0.12$ \\
\hline Oleic acid $(18: 1)$ & $20.75 \pm 2.06$ & $16.15 \pm 0.32$ & $12.88 \pm 0.34$ & $16.84 \pm 1.18$ \\
\hline Vaccenic acid $(18: 1)$ & $7.17 \pm 0.01$ & $5.90 \pm 0.41$ & $4.88 \pm 0.52$ & $6.11 \pm 0.14$ \\
\hline Eicosenic acid $(20: 1)$ & $1.25 \pm 0.18$ & $0.71 \pm 0.05$ & $0.75 \pm 0.06$ & $0.62 \pm 0.33$ \\
\hline Erucic acid $(22: 1)$ & $1.23 \pm 0.31$ & - & - & - \\
\hline Total MUFA & $31.26 \pm 2.99$ & $25.83 \pm 1.85$ & $21.58 \pm 1.17$ & $25.7 \pm 1.77$ \\
\hline \multicolumn{5}{|l|}{ Polyunsaturated fatty acids } \\
\hline Tetradecadienoic acid $(14: 2)$ & $1.35 \pm 1.09$ & $0.47 \pm 0.17$ & $0.42 \pm 0.01$ & $0.52 \pm 0.06$ \\
\hline Hexadecadienoic acid $(16: 2)$ & $0.52 \pm 0.41$ & $0.98 \pm 0.36$ & $0.65 \pm 0.19$ & $0.83 \pm 0.13$ \\
\hline Hexadecatrienoic acid $(16: 3)$ & $0.85 \pm 0.27$ & $0.83 \pm 0.02$ & $1.07 \pm 0.03$ & $1.18 \pm 0.03$ \\
\hline Linoleic acid (18 : 2) & $16.95 \pm 0.99$ & $20.60 \pm 0.25$ & $17.17 \pm 0.78$ & $21.77 \pm 0.93$ \\
\hline Linolenic acid (18:3) & $2.17 \pm 0.10$ & $3.34 \pm 0.67$ & $3.99 \pm 0.13$ & $2.77 \pm 0.19$ \\
\hline Eicosadienoic acid (20:2) & $0.52 \pm 0.24$ & $1.49 \pm 0.13$ & $1.22 \pm 0.13$ & $2.81 \pm 1.17$ \\
\hline Eicosatrienoic acid (20:3) & $1.92 \pm 0.55$ & $2.21 \pm 0.76$ & $4.69 \pm 1.22$ & $1.49 \pm 0.02$ \\
\hline Arachidonic acid (20:4) & $4.69 \pm 1.29$ & $2.65 \pm 0.00$ & $3.39 \pm 0.38$ & $3.43 \pm 0.83$ \\
\hline Eicosapentaenoic acid $(20: 5)$ & $0.56 \pm 0.02$ & $0.52 \pm 0.22$ & $1.83 \pm 0.22$ & $0.22 \pm 0.03$ \\
\hline Docosadienoic (22: 2) & - & $0.42 \pm 0.38$ & $1.22 \pm 0.22$ & - \\
\hline Docosatrienoic acid $(22: 3)$ & $1.45 \pm 0.45$ & $2.12 \pm 0.17$ & $2.14 \pm 0.03$ & $0.98 \pm 0.11$ \\
\hline Adrenic acid (22:4) & $2.08 \pm 0.45$ & $1.81 \pm 0.18$ & $2.30 \pm 0.03$ & $1.02 \pm 0.05$ \\
\hline Docosapentaenoic acid (22:5) & $0.88 \pm 0.46$ & $2.23 \pm 0.03$ & $2.30 \pm 0.07$ & $1.40 \pm 0.09$ \\
\hline Docosahexaenoic acid $(22: 6)$ & $2.70 \pm 0.53$ & $0.06 \pm 0.02$ & $0.16 \pm 0.02$ & $1.98 \pm 0.11$ \\
\hline Total PUFA & $36.64 \pm 6.85$ & $39.73 \pm 3.36$ & $42.55 \pm 3.46$ & $40.4 \pm 3.75$ \\
\hline
\end{tabular}

The highest amount of eicosapentanoic acid (EPA) was found in treatment-3 (1.83 \pm $0.22 \%)$ and the lowest in treatment-4 $(0.22 \pm 0.03 \%)$ (Fig. 7). The amount of eicosapentaenoic acid in treatment-3 was significantly different than other treatments. 


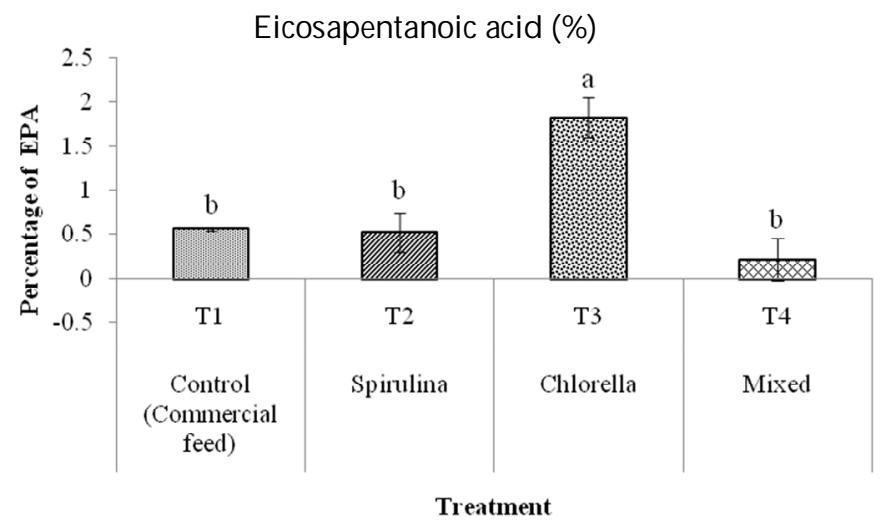

Fig. 7. Variations of eicosapentanoic Acid in Nile tilapia cultured in different types of treatment during 24 weeks of culture period. Values are mean \pm SEM of duplicate groups of 2 samples. Means in the same column with different superscripts are significantly different at $\mathrm{p}<0.05$.

The highest amount of docosahexaenoic acid (DHA) was found in treatment-1 (2.70 \pm $0.53 \%)$ and the lowest in treatment-2 $(0.06 \pm 0.02 \%)$. Fig. 8 shows that the amount of docosahexaenoic acid was highly significant in treatment-1 (commercial feed) than treatment-2 and treatment-3.

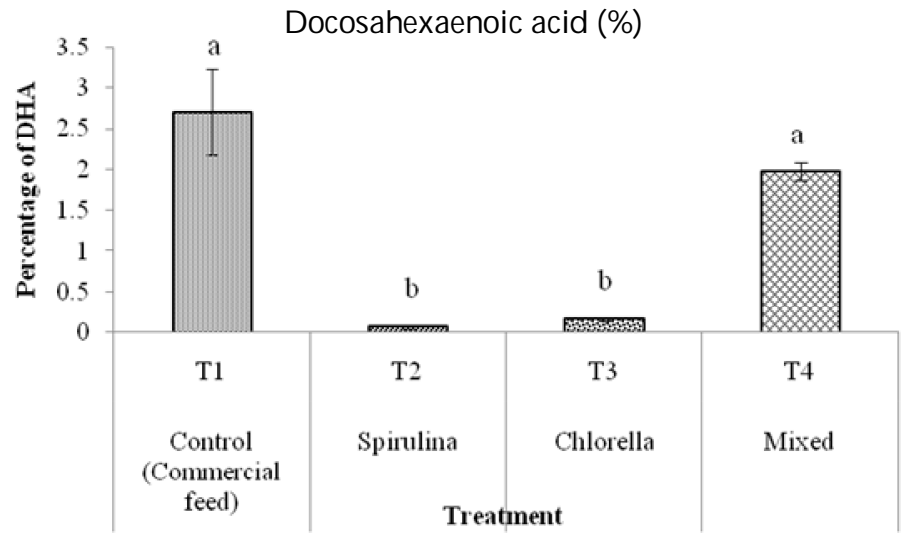

Fig. 8. Variations of docosahexaenoic acid in Tilapia cultured in different types of treatments during 24 weeks of culture. Values are mean \pm SEM of duplicate groups of 2 samples. Means in the same column with different superscripts are significantly different at $\mathrm{p}<0.05$.

Rasoarahona et al.(29) observed $1-3 \%$ of eicosapentaenoic acid and $4-11 \%$ docosahexaenoic acid from three tilapia species (O. macrochir, T. rendalli and O. niloticus) in Madagascar during three seasons. Visentainer et al.(31) found 0.1 to $2.5 \mathrm{mg} / \mathrm{g}$ of EPA, 9.9 
to $26.1 \mathrm{mg} / \mathrm{g}$ of DHA and 6.5 to $59.3 \mathrm{mg} / \mathrm{g}$ LNA from O. niloticus fillets using different concentrations of flaxseed oil was used.

Docosahexaenoic acid (\%)

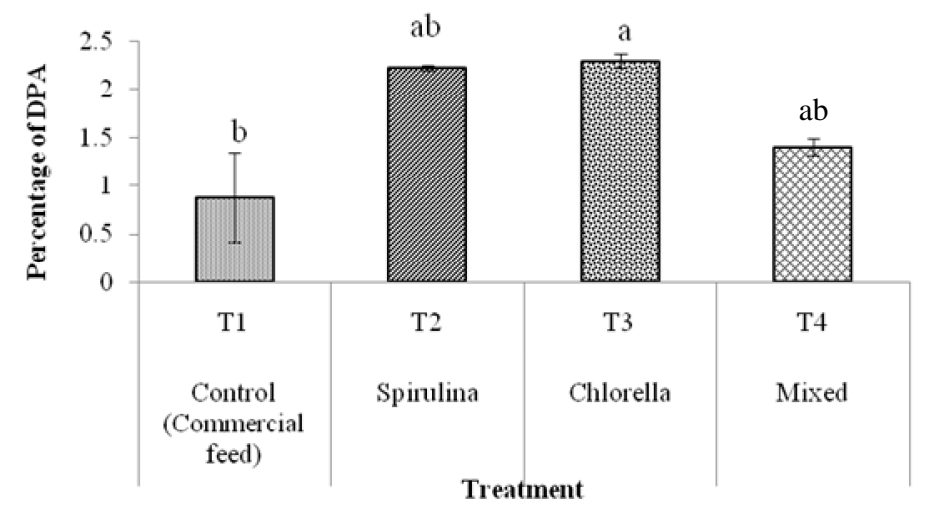

Fig. 9. Variations of docosapentaenoic acid in Tilapia cultured in different types of treatments during 24 weeks of culture. Values are mean \pm SEM of duplicate groups of 2 samples. Means in the same column with different superscripts are significantly different at $\mathrm{p}<0.05$.

The highest amount of docosapentaenoic acid was found in treatment-3 $(2.30 \pm 0.07)$ and lowest in treatment- $1(0.88 \pm 0.46)$. Between treatment- 1 and treatment- 3 , significant differences were observed (Fig. 9).

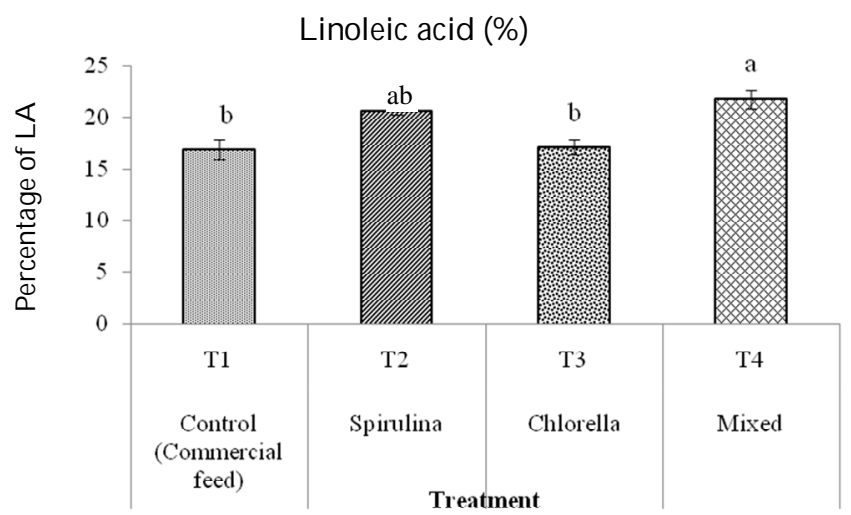

Fig. 10. Variations of linoleic acid in tilapia cultured in different types of treatments during 24 weeks of culture. Values are mean \pm SEM of duplicate groups of 2 samples. Means in the same column with different superscripts are significantly different at $p<0.05$

The highest amount of linoleic acid was found in treatment-4 with mixed phytoplankton $(21.77 \pm 0.93 \%)$ and the lowest in treatment- 1 with control $(16.95 \pm 0.99 \%)$. The treatment- 4 was significantly different than treatment- 1 and treatment-3 (Fig. 10). Petenuci et al.(32) observed that the amount of linoleic acids using fishbone flour was 
GROWTH PERFORMANCE AND FATTY ACID PROFILE OF NILE TILAPIA

$109.60 \pm 11.60 \mathrm{mg} / \mathrm{g}$ in Nile tilapia. Among 19 unsaturated fatty acid, highest concentration of PUFAs was measured from treatment-3 $(42.55 \pm 3.46 \%)$ fed with Chlorella vulgaris and the lowest concentration was observed from control $(36.64 \pm 6.85 \%)$. Level of MUFAs ranged from $21.58 \pm 1.17$ (fed with Chlorella vulgaris) to $31.26 \pm 2.99 \%$ (control).

\section{Conclusions}

Growth of Nile tilapia can cope with different types of physiochemical parameters such as temperature, $\mathrm{pH}, \mathrm{DO}$, conductivity, total dissolved solids, light intensity and so on. From the experiment conducted it was observed that the length and weight of tilapia fish varied with different phytoplankton and plant derivatives. The best growth performance was observed in the cultures with Chlorella and Spirulina. Chlorella has the best proximate composition for human nutritional interest and thus it was found to be the better option to produce healthy fish for human consumption. Culture of Nile tilapia with different phytoplankton in small ponds might be useful to improve growth and to enhance fatty acid composition of producing fish and for the well-being of consumers as well.

\section{Acknowledgements}

The authors are grateful to Jahane Nijam Bohumukhi Matshya Hatchery, Manikgonj, Bangladesh for their cooperation during fry collection and transportation.

\section{References}

1. El-Sayed AFM 1999. Alternative dietary protein sources for farmed tilapia, Oreochromis spp. Aquaculture 179: 149-168.

2. FAO 2014. FAO Year Book 2012 - Fishery and Aquaculture Statistics. Food and Agriculture Organization of the United Nations, Rome, Italy, 105.

3. Abdel-Tawwab M, AE Abdelghany and MH Ahmad 2007. Effect of diet supplementation on water quality, phytoplankton community structure and the growth of Nile tilapia, Oreochromis niloticus (L.), common carp, Cyprinus carpio (L.), and silver carp, Hypophthalmichthys molitrix (V.), polycultured in fertilized earthen ponds. J. Appl. Aquacult. 19: 1-24.

4. Jackson AJ, BS Copper and AJ Matty 1982. Evaluation of some plant proteins in complete diets for the tilapia Sarotherodon mossambicus. Aquaculture 27: 97-109.

5. Azaza MS, F Mensi, J Ksouri, MN Dhraief, B Brini, A Abdelmouleh and MM Kraiem 2008. Growth of Nile tilapia (Oreochromis niloticus L.) fed with diets containing graded levels of green algae ulva meal (Ulva rigida) reared in geothermal waters of southern Tunisia. J. Appl. Ichthyol. 24: 202-207.

6. New MB 1999. Global aquaculture: Current trends and challenges for the 21st century. World Aquaculture 30: 8-13. 
7. Munuswamy N, J Mertens, C. De Walsche and HJ Dumont 1992. Lipid classes and fatty acid profiles in cryptobiotic cysts of Streptocephalus dichotomus and Streptocephalus proboscideus (Crustacea: Anostraca). Hydrobiologia 231: 65-68.

8. Goodnight SH Jr., WS Harris, WE Connor and DR Illingworth 1982. Polyunsaturated fatty acids hyperlipidemia, and thrombosis. Arteriosclerosis 2: 87-113.

9. Falk-Petersen S, JR Sargent, J Henderson, EN Hegseth, H Hop and YB Okolodkov 1998. Lipids and fatty acids in ice algae and phytoplankton from the Marginal Ice Zone in the Barents Sea. Polar Biol. 20: 41-47.

10. Hile R 1936. Age and growth of the Cisco, Leucicthys artedi (Le Seur), in lakes of the Northeastern highlands, Wisconsin. Bull. Bureau of Fisheries 48: 211-217.

11. Hawkins AD, NM Soofiani and GW Smith 1985. Growth and feeding of juvenile cod (Gadus morhua L.). J. Cons. Int. Explor. Mer 42: 11-32.

12. Hewett SW, CE Kraft and BL Johnson 1991. Consumption, growth and allometry: A comment on Boisclair and Leggett. Can. J. Fish. Aquat. Sci. 48: 1334-1337.

13. Hewett, SW and BL Johnson 1992. A generalized bioenergetics model of fish growth for microcomputers, version 2.0. University of Wisconsin Sea Grant Institute, Madison, WI. UW Sea Grant Tech. Rep. WIS-SG-92-250. p. 79.

14. Cheikyula JO and PC Ofojekwu 2003. Growth responses and survival of the gold fish Carassius auratus (Cyprinidae) fry reared on Moina (Cladocera) and Cyclops (Copepoda). J. Aqua. Sci. 18(1): 43-46.

15. Murua H, G Kraus, F Saborido-Rey, PR Witthames, A Thorsen and S Junquera 2003. Procedures to estimate fecundity of marine fish species in relation to their reproductive strategy. J. Northw. Atl. Fish. Sci. 33: 33-54.

16. Nichols DS, PD Nichols and TA McMeekin 1993. Polyunsaturated fatty acids in Antarctic bacteria. Antarct. Sci. 5(2): 149-160.

17. Hussain MG 2004. Farming of Tilapia: Breeding plans, mass seed production and aquaculture techniques. 1st (eds), pp. 149 published by Habiba Akter Hussain, 55 Kristawpur, Mymensingh 2200 Bangladesh.

18. Dagne A, F Degefu and A Lakew 2013. Comparative growth performance of mono-sex and mixed-sex Nile tilapia (Oreochromis niloticus L.) in pond culture system at Sebeta, Ethiopian. Int. J. Aquacult. 3(7): 30-34.

19. Charo-Karisa H, MA Rezk, K Bovenhuis and H Komen 2004. Effects of rearing conditions on low temperature tolerance of Nile tilapia, Oreochromis niloticus, juveniles. In: Proceedings of the 6th International Symposium on Tilapia in Aquaculture, Manila, Philippines, 12-16 September 2004. pp. 30-41.

20. Khallaf EA, M Galal and M Athuman 2003. The biology of Oreochromis niloticus in a polluted canal. Ecotoxicology 12: 405-416.

21. Chakraborty BK and JA Mirza 2008. Growth and yield performance of threatened Singi, Heteropneustes fossilis (Bloch) under semi intensive aquaculture of Bangladesh. J. Fish. Soc. Taiwan 35: 117-125.

22. Olvera-Novoa MA, F Pereira-Pacheco, L Olivera-Castillo, V Perez-Flores, L Navarro and JC Samano 1997. Cowpea (Vigna unguiculata) protein concentrate as replacement for fish meal in diets for tilapia (Oreochromis niloticus) fry. Aquaculture 158: 107-116. 
23. Doolgindachabaporn S 1994. Development of optimal rearing and culturing system for Climbing perch, Anabas testudineus (Bloch). Doctoral Thesis, University of Manitoba, Canada. pp. 468.

24. Akand AM, ML Mia and MM Haque 1989. Effect of dietary protein level on growth, feed conversion and body composition of Shingi (Heteropneustes fossilis Bloch). Aquaculture 77: $175-180$

25. Ogunji JO and M Wirth 2000. Effect of dietary protein content on growth, food conversion and body composition of Oreochromis niloticus fingerlings, fed fish meal diet. J. Aquacult. Trop. 15(4): 381-389.

26. Patricio EP 2004. Evaluation of growth, production, and cold tolerance of four varieties of tilapia. M.Sc. Thesis, Louisiana State University, USA. pp. 76.

27. Dan NC and DC little 2000. Over-wintering performance of Nile tilapia, Oreochromis niloticus (L.) brood fish and seed at ambient temperatures in northern Vietnam. Aquacult. Res. 31(6): 485-493.

28. Duponchelle F, P Cecchi, D Corbin, J Nuñez and M Legendre 2000. Variations in fecundity and egg size of female Nile tilapia, Oreochromis niloticus, from man-made lakes of Côte d'Ivoire. Environ. Biol. Fish. 57: 155-170.

29. Rasoarahona JRE, G Barnathan, JP Bianchini and EM Gaydou 2005. Influence of season on the lipid content and fatty acid profiles of three tilapia species (Oreochromis niloticus, $O$. macrochir and T. rendalli) from Madagascar. Food Chem. 91: 683-694.

30. Andrade AD, JV Visentainer, M Matsushita and NE de Souza 1997. Omega-3 fatty acids in baked freshwater fish from south of Brazil. Arch. Latinoam. Nutr. 47(1): 73-76.

31. Visentainer JV, NE de Souza, M Makoto, C Hayashi and MRB Franco 2005. Influence of diets enriched with flaxseed oil on the $\alpha$-linolenic, eicosapentaenoic and docosahexaenoic fatty acid in Nile tilapia (Oreochromis niloticus). Food Chem. 90: 557-560.

32. Petenuci ME, FB Stevanato, JE Visentainer, M Matsushita, EE Garcia NE de Souza and JV Visentainer 2008. Fatty acid concentration, proximate composition, and mineral composition in fishbone flour of Nile tilapia. Arch. Latinoam. Nutr. 58(1): 87-90. 